\title{
China's diaspora engagement policy and its powerful effect outside its borders
}

Edition 8, 2021

Associate Professor Yan Tan

DOI: 10.37839/MAR2652-550X8.9

The overall Chinese diaspora population is one of the world's largest at more than 60 million. Since President Xi Jinping came to power in November 2012, China's diaspora policy has transnational elements that are increasingly mainstream.

According to a strategic plan issued by the State Council of China in 2015 called Made in China 2025, building an advanced manufacturing industry would allow China to sustain its economic growth, safeguard national security, and boost global political and economic influence. China's manufacturing sector is undergoing a crucial transition, shifting from the low to the high end of the industrial chain. Tapping scientific, professional, and entrepreneurial skills in the diaspora has solidified as a strategic aim. All levels of government have sought to attract such talent-prioritising the knowledge network over capital flow, as have other economically advanced economies such as the US, Singapore, and Australia.

In 2018, the Communist Party Central Committee called on all diaspora to help 'realise the great rejuvenation of the Chinese nation and build a community with a shared future for humanity,' by 'telling Chinese stories, assisting economic development of China, upholding the greater national interests [meaning national reunion], and promoting Chinese culture'. This call elucidates the scope of China's current engagement policy, which goes beyond domestic economic development interests and extends to transnational political, social, diplomatic, and cultural 
domains.

A dominant economic and political power, China has brought substantial dynamics to bear on global and regional power structures. Its diaspora policy is by no means driven by its domestic interests alone; it evolves globally, shaped by complex political, economic, and social forces (especially those involving destination countries), and has major implications for other polities on the world stage.

This article discusses two fundamental trends or challenges in China's diaspora engagement policies:

- the rise of 'recruiting highly skilled talents' (zhaocai yinzhi), replacing an earlier practice of 'attracting foreign businesses and capital investment' (zhaoshang yinzi).

- the move from tapping diaspora capital investment for economic development (1980s and 1990s) to emphasising diaspora as promoting soft power (since 2000).

This article seeks to understand these changes, challenges and potential pathways from a transnational perspective.

A transnational perspective portrays policy in terms of institutions and embedded transnational linkages that are multi-faceted (economic, social-cultural, political) and multi-scalar (with emphasis on the macro-scale in this study) that connect countries of origin and destination. Diaspora policy reflects 'transnationalism from above', devised by governments to engage diasporas at a distance in favor of political, economic, and social dominance by existing elites of development interests in homelands, and shaped by 'transnationalism from below'.

The discussion is based on recent in-depth interviews with key informants, including Chinese government officials, public institution servants, leaders of nongovernmental organisations (NGOs), and Chinese researchers active in overseasChinese research. In December 2018 and January 2019, I (with the great assistance 
of a research associate and a $\mathrm{PhD}$ student under my supervision) led face-to-face interviews across 10 cities in five municipalities or provinces: Beijing, Shanghai, Zhejiang, Guangdong, and Jiangsu, each being a major source of Chinese emigrants. We posed semi-structured questions to collect information on the recent changes in objectives, scope, and principal components of China's diaspora engagement, possible factors contributing to the changes, and critical issues and interventions. Further, the answers were cross-referenced with existing statements drawn from the policy and previous research.

\section{Attracting 'Top Talents'}

\section{Background}

This century, tapping advanced science and professional skills has solidified as an instrumental aim of Chinese diaspora strategy. Since China's 2000 acceptance into the World Trade Organisation, its economic development has entered a transnational period. Traditional industries, dominated by labor-, resource-, or capital-intensive manufacturing sectors, have struck natural- and human-resource constraints (land, water, energy, emerging workforce shortages). High-tech industries are urgently needed to sustain the momentum of industrialisation and urbanisation. China's rising economy and increased investment in innovative and entrepreneurial sectors have drawn many back from destination countries, hit by shrinking job opportunities and economic downturns since the global financial crisis. All levels of government in China have implemented policies to favor returning talent; but the emphasis is now less on enticing back international students, and more on attracting workers of the highest calibre with advanced scientific and professional skills.

\section{Interview analysis}

The narratives of talent engagement in China largely focused on 'top talent' programs and their challenges, notably the Thousand Talents Plan (TTP) established 
in 2008, aimed at recruiting leading international scientists and research professionals, technological innovators, and entrepreneurs. 'About 90 percent of TTP recipients are reported to be overseas Chinese' [government official 3, Zhejiang, male, 40s]. However, 'attracting top talents becomes quite sensitive now' [government official 5, Beijing, female, 50s]. Respondents attributed this sensitivity to China's relations with Western countries, particularly the intensifying trade war with the US. 'Talents holding US nationality could not come back to China, due to the tense Sino-American relationship. In fact, the majority of talents who have returned to China or intended to serve China under arrangements are Chinese who had been living in the US' [government official 5, Beijing, female, 50s]. But an NGO leader ascribed the sensitivity to breaches of intellectual property (IP): 'The US has to protect intellectual property. It cannot accuse the Thousand Talents if they did not breach the intellectual property rights ... If China respects IP rights, it will attract more people back' [NGO leader 2, Shanghai, male, 50s].

\section{Transnational perspective}

What has been identified as the global war for talent has intensified since 2008, as a result of 'unprecedented financial crisis, economic slow-down, and massive [industrial] restructuring'. China's strategy for engaging diaspora talent, exemplified in the TTP, runs counter to the interests of some destination countries as they strive to maintain vanguard positions in the fourth industrial revolution with its breakthroughs in fields like Artificial Intelligence, robotics, 3D printing, genetic engineering, and quantum computing. Such programs have engendered serious friction with the US, which accuses China of seducing distinguished researchers in these high-tech fields into illegal transfers of technology that breach IP rights. Confronting the US's accusation, a spokeswoman at China's Embassy in Washington claimed that the Chinese government firmly opposed any breach of scientific integrity and ethnics and it is irresponsible and ill-intentioned to link illegal behaviors of individuals to the talent plan of a nation. Since 2018, China's talent plan has retreated to a lower profile to reduce its sensitivity; information on TTP and 
its beneficiaries have become inaccessible on Chinese websites since mid-2018. These shifts do not, however, ease tensions between China and the US under conditions of the trade war. Chinese-American academics and engineers (i.e. Chinese with American citizenship) whose work involves TTP in China have been arrested or removed from their jobs in the US, scientific communication has declined, and even visas for Chinese students to study in the US have been restricted.

In present circumstances attracting talent is clearly no longer a 'bring in' strategy confined to domestic development imperatives. Rather, it is an essential component of, and one of the triggers for, competition and attempts at repositioning by global powers in a high-tech era. In this regard, China's talent programs occupy a transnational social space where:

- attracting talent is not decided exclusively by domestic development needs but also strongly shaped by international relations;

- the function of attracting talent is not restricted to socio-economic transnational linkages between diaspora individuals and their home country, but embodies the relationship between countries of origin and destination; and

- the effects of attracting talent go far beyond national boundaries and contribute to international competition in this era of the fourth industrial revolution.

\section{Building soft power}

\section{Background}

Soft power is a term widely used to characterise assets that a country deploys to attract individuals and win foreign publics through appeal to shared values. Over four decades, China has experienced dramatic economic and social development, 
witnessed massive emigration, and risen as a major global power, economically and politically. It has therefore increasingly sought to supplement its traditional use of hard power with soft power that is intended to 'gradually change China's image in the international society from negative to neutral to positive'. Recent studies argue that this quest constitutes a major change away from the conventional policy that engaged diaspora primarily for national economic development.

Since President Xi's accession in 2012 stressing public diplomacy for shaping the country's soft power and disseminating Chinese culture and social values worldwide has become a high priority. Xi quickly advocated for public diplomacy through telling positive stories about China, which have since become a central tenet of China's soft power. China now invokes a 'national imaginary': of those in the diaspora deployed as 'public diplomats' or lobbyists to tell good stories about China's intentions and qualities.

\section{Interview analysis}

Our interviews are consistent with this transformation: 'In the past, China's state of economic development focused on attracting foreign capital investment and advanced technology. This trend has taken a complete turn to [the] export of Chinese soft power in recent years. Presently, China is actively reaching out to the international community to facilitate the exchange of technology, wisdom, and experience, establish a community with a shared future for all mankind, promote integration of overseas Chinese into the destination societies, and enable them to tell good Chinese stories' [Researcher 6, Beijing, female, 50s].

As detailed below, while the narratives are not without precedent in recognising such transformation, they draw out three stages in recruitment as public diplomats in diaspora: embracing the transnational nature of diasporas, promoting their integration in destinations, and engaging them in 'story telling.' 


\section{Embracing transnationality}

At this first stage of recruitment, our respondents tend to believe that diasporas can contribute to the home country even without returning. One asked: 'Why should China bring diasporas back? Yes, returnees may bring technology back that benefits development, but staying overseas can help exporting China's culture and ideology and promoting China's image' [NGO leader 1, Beijing, male, 30s]. Some researcher respondents proposed that diaspora is China's human capital functioning in a 'holistic field' (quanyu) not restricted to China's territory [Researcher 7, Beijing, male, 50s]. Another researcher reaffirmed and clarified the assertion: 'China is exporting its human and financial capital. We should use the human capital in a holistic field, which is a global field rather than confined to China. Whoever serves China's interests should be included in China's human capital, wherever they reside' [Researcher 8, Beijing, female, 40s]. These narratives in fact echo China's most recent talent policy, which primarily focuses on attracting 'top talents' to return, and encouraging 'ordinary' diaspora members to stay in destination countries.

\section{Integration in destinations}

At this second stage of recruitment for public diplomacy, stakeholders believe that integration at destinations can benefit both countries. In-depth surveys reveal China's strong intention to promote this integration: 'The Chinese government should build platforms for them (diaspora members) to integrate quickly in their destination, achieving self-development and contributing to the local society. This is a win-win situation, because successful integration into destination enhances capacity to reward their motherland' [All-China Federation of Returned Overseas Chinese (ACFROC) leader 1, Beijing, female, 50s]. Another respondent answered passionately: 'Doing so (promoting integration to destination) will improve the ability to bridge with friendship the two countries, and to spread Chinese thinking and development.' [Researcher 6, Beijing, female, 50]. Respondents considered that 'integration to destination' benefits homeland through exporting values and culture, 
rather than merely importing material capital.

\section{Telling stories}

As for the third stage, our respondents confirm that current policies aim for public diplomats 'telling stories' in the diaspora. Two variants emerge in the 'telling stories' theme: individuals telling 'small stories', and media promoting more general stories about China. On small stories, one respondent commented that 'foreigners do not care about the big story such as China's national rejuvenation; rather they are interested in small stories relevant to their own life' [ACFROC leader 2, Beijing, female, 40s]. Some examples were given to explain how to tell these. 'They [in the diaspora] can undertake a series of activities to familiarise foreigners with Chinese culture. For instance, [restaurant people] can teach foreign folk how to cook Chinese dishes, or offer discounts to those who are familiar with some aspects of Chinese culture or speak a little Chinese' [ACFROC leader 3, Zhejiang, male, 50s]. Theoretically, Chinese media can simultaneously tell China's stories to foreigners and maintain or strengthen diaspora solidarity. But we uncovered a consensus that China is not successful in its foreign communication efforts, including engaging diasporic media. A researcher respondent put it straightforwardly: "The government needs to admit that its foreign communication work is a failure' [Researcher 8, Beijing, female, 40s]. Some NGO leaders agreed: 'It is hard to find harmonious coexistence of diasporic media and local mainstream media in destination countries, especially Western countries, because they think and talk in different ways' [NGO leader 3, Jiangsu, male, 50s].

\section{Transnational perspective}

China's accelerating global media initiative is an active way of its exercise of soft power. China appears to have engaged diasporic media proactively in constructing soft power at the very beginning, which turned out to be ineffective in the opinion of stakeholders. Their view differs from that of Professor Clive Hamilton and Dr Mareike Ohlberg who claimed in their 2020 book that the Communist Party of China 
(CPC) has succeeded in controlling Chinese-language media overseas and suppressing many voices critical of China's stance on human rights. The term 'failure' used by the respondents refers to a limited understanding of how to apply the concept of soft power to media operations such as exporting propaganda outside its borders. As one study has put it, soft power's 'implementation and efficacy have mostly been examined in the context of Chinese foreign policy and China's involvement in international politics. These investigations have brought us no closer to an explanation of how the concept is understood and applied in the domain of media and communication'. Moreover, China regards diasporic Chinese-language media as a key node in global communications, whereas it neglects an intrinsic impediment for these media in global communication with foreigners: the language barrier. Touching on this issue, one respondent emphasised a shift toward 'bilingual media' and 'employing local staff.'

China's engagement of those in diaspora as public diplomats has had a mixed effect on China's soft power. Evidence can be found from many episodes in foreign affairs, ranging from the 2008 Olympic torch relay when many in the Chinese diaspora reacted strongly against Western media coverage of the Tibet riots to recent Hong Kong student protests about the extradition bill, where mainland students in the diaspora quickly confronted Hong Kong students on campuses, mobilised and facilitated by China's social media, notably WeChat and Weibo. However, in Australia this skirmish in the domain of public and civil diplomacy spiraled into a real diplomatic issue when the Chinese Consulate-General in Brisbane publicly praised the actions of the mainland Chinese students in Australia. In response to this, Australia's Foreign Minister warned diplomats to respect rights of free speech and protest in Australia. This escalated to heated discussion of foreign interference from China on Australian university campuses. How to keep public diplomacy in the domain of civic is a pressing lesson for China to learn. 


\section{Concluding remarks}

The study provides new insights on diaspora policy from a transnational perspective, of which we highlight two. First, the narratives show that China's policy on soft power is intrinsically transnational. Soft power is inherently transnational, as it is characterised by a transnational purpose of improving China's image in the international community. It seeks to position itself more advantageously in the global power structure: a set of transnational forces shaping its design and function (such as political ideology and culture in destination countries). This calls for a transnational function of building cultural and socio-political linkages with China's 'public diplomats' in diaspora, and a transnational influence on governments' and people's understanding of and attitudes toward China in foreign territories, in both positive and negative ways.

The second major insight from the interviews is that the talent programs, while seemingly domestic, actually reflect transnational nature as they are embedded in global power relations mediated primarily by the uncertain and complex relations between China, the US, and other developed countries. Attracting talented individuals once appeared to be a traditional 'bring in' policy with a particular focus on research and innovation programs and the universities, research institutes and high-tech innovation parks that host the programs. Our interviews, however, demonstrate that the focus of talent policy has shifted outside of the country: talent policy now plays a significant role in repositioning China in the changing global power structure, and is influenced by transnational forces, especially international competition for talent, intellectual property regulations on hi-tech transfer, Sino-US contestation, and national securities.

In conclusion, China's diaspora policy is shaped by a constellation of transnational factors: changing global and regional power structures due to economic, technological, and talent-retaining competition, and uncertain international relations in the new technological era. To engage with diasporas effectively, China is 
deploying all-dimensional and multi-scale use of linkages, expanding from economic to socio-cultural and political spheres, especially when attracting top talent, and engaging diaspora in public diplomacy. China's policy not only shapes its internal development but also influences global sentiment and brings new dynamics to bear global on power relations (most saliently with the US, perhaps), especially through talent attraction and soft power. These findings contribute to the literature on Chinese-state-diaspora relations and combine to suggest that China's diaspora policy, practice, and outcomes have powerful new effect across national borders. Understanding such dramatic shifts, challenges, and directions of Chinese diaspora policies enhances understanding and potential cooperation. This study contributes to the theory of transnationalism by emphasising the dynamic and relational elements in transnational analysis to comprehend the new complexity of the diaspora-development nexus.

Image: Chinatown New York. Credit: Martin Solli/Flickr. 